\title{
Genetic correlations between heifer subsequent rebreeding and age at first calving and growth traits in Nellore cattle by Bayesian inference
}

\author{
A.A. Boligon, F. Baldi and L.G. Albuquerque \\ Faculdade de Ciências Agrárias e Veterinárias, \\ Universidade Estadual Paulista "Júlio de Mesquita Filho", \\ Jaboticabal, SP, Brasil \\ Corresponding author: A.A. Boligon \\ E-mail: arioneboligon@yahoo.com.br
}

Genet. Mol. Res. 11 (4): 4516-4524 (2012)

Received January 9, 2012

Accepted May 22, 2012

Published October 17, 2012

DOI http://dx.doi.org/10.4238/2012.October.17.2

\begin{abstract}
We estimated heritability for subsequent rebreeding (SR) of heifers and genetic correlations between this trait and weaning weight (WW), weight gain from weaning to yearling (WG), age at first calving (AFC), and mature cow weight (MW), in order to evaluate whether SR could be included as selection criterion in Nellore cattle. The SR of heifers was defined by attributing a value of 1 (success) or 0 (failure) to heifers that calved or not, respectively, given that they had calved once before. Records from 127,430 Nellore animals were analyzed. Genetic parameters were estimated by Bayesian inference using a nonlinear (threshold) animal model for SR and a linear animal model for the other traits in three-trait analyses, including SR and WW in all analyses. The posterior means of heritability for SR, WW, WG, AFC, and MW were $0.18 \pm 0.02,0.21 \pm 0.01,0.30 \pm 0.01,0.21 \pm 0.01$, and 0.45 \pm 0.04 , respectively. The posterior mean estimates of genetic correlations between SR and WW, WG, AFC, and MW were $-0.20 \pm$ $0.06,0.31 \pm 0.07,-0.77 \pm 0.05$, and $-0.15 \pm 0.09$, respectively. Based
\end{abstract}


on these genetic correlations, selection for higher gains for WG and younger AFC should result in an increase in heifer SR rates, while long-term selection for increasing WW should promote unfavorable responses in heifer SR. The use of breeding values for heifer SR as a selection criterion of Nellore bulls could increase heifer SR rate without significant changes in MW.

Key words: Bayesian inference; Beef cattle; Fertility; Genetic parameters

\section{INTRODUCTION}

Subsequent rebreeding (SR) of primiparous females is a critical aspect of productivity in the Brazilian beef cattle herd. Even under favorable conditions, the pregnancy rate for primiparous females is lower than that for cows and varies from 53.3 to $87.5 \%$ (Vieira et al., 2005). According to Pereira (2008), the environmental effects (climate and nutrition) that generally affect the performance of beef cattle and the large physiological demands imposed by lactation and growth on primiparous females are associated with low SR rates of heifers. Increasing SR not only enhances farm income but also increases production efficiency by providing more animals from which to select replacements (Buddenberg et al., 1989).

In general, low heritability estimates for female reproductive traits indicate that environmental differences are the main cause of variation, a fact impairing the inclusion of these traits in selection indices designed to improve the reproductive performance of beef cattle. Using data from Nellore (Bos indicus) animals in a nonlinear animal model and Bayesian inference, Silva et al. (2008) have reported a heritability of $0.16 \pm 0.05$ for SR in heifers that calved for the first time at approximately 24 months of age. Similarly, Pereira (2008) obtained a heritability of $0.15 \pm 0.04$ for SR in primiparous Nellore females exposed at 24 months of age.

Studies associating heifer SR with traits commonly used as selection criteria are scarce. Knowledge about the magnitude of the genetic correlations of heifer SR with age at first calving (AFC) and growth traits are important because it indicates whether the criteria used for beef cattle selection are influencing the reproductive performance of heifers. For instance, Pereira (2008) have reported a high and negative genetic correlation estimate $(-0.66$ \pm 0.09 ) between the SR of females and yearling weight in Nellore cattle. Studies in the literature (Meyer et al., 2004; Boligon et al., 2009, Regatieri et al., 2012) have suggested that selection for higher weights at younger ages may lead to larger animals at maturity owing to a correlated response, with these animals having greater nutritional requirements (Jenkins and Ferrell, 1994). These greater nutritional requirements, together with the large physiological demands of lactation and growth, may contribute to low SR rates in primiparous females. In this respect, no studies associating heifer SR with mature cow weight (MW) have been published. The objective of this study was to estimate heritability for heifer SR and genetic correlations between this trait and weaning weight (WW), weight gain from weaning to yearling (WG), AFC, and MW to evaluate the possible use of SR of primiparous females as a selection criterion in Nellore cattle. 


\section{MATERIAL AND METHODS}

\section{Description of data}

Data obtained from 127,430 Nellore animals born between 1990 and 2006 within the cattle-raising herd of Agropecuária Jacarezinho Ltda., Valparaíso, São Paulo, Brazil, were used in the study. With respect to reproductive management, the animals participated in two breeding seasons: the first comprised the period from February to April (60 days), during which all females of 15-16 months of age were exposed to bulls to identify sexually active animals. The first season was started in 1990 and included only heifers. The second breeding season (normal breeding season) started in the second half of November and lasted 60 days. All females of reproductive age participated in this breeding except for heifers that conceived in the first season. Heifers that had not conceived in the first breeding season had a second opportunity the following season and those that did not conceive in the second season (second opportunity) were culled.

Heifer pregnancy was diagnosed by rectal palpation approximately 60 days after the end of the first breeding season. The following culling criteria for females were used: consecutive reproductive failure in the first and normal season; lack of conception within 1 year; low progeny performance (WW), and at a lower frequency, health problems. Females that were close to the likely date of calving were transferred to maternity paddocks. After calving, the calves, which were divided according to gender and age, and their mothers were transferred to another site (pasture) and remained together until weaning, forming a management group at weaning that consisted of an average of 110 animals. Calves were weaned at about 7 months of age. Some calves were regrouped and remained together until approximately 18 months of age (yearlings).

SR was defined by attributing a value of 1 (success) or 0 (failure) to heifers that had calved or not, respectively, given that they had calved once before. Information from heifers that conceived during the first breeding season was also included in the analysis. The maximum age for rebreeding was 42 months. The MW was measured immediately after calving and was defined as the first cow weight recorded after 4 years of age. The following traits were also evaluated: WW, WG, and AFC.

Several systematic effects were considered: SR: contemporary groups (CGs) (herd and year of birth of the cow, calf sex, and year of birth of first offspring) and linear effect of the rest period (number of days after calving until the beginning of the second breeding season) as covariate; WW: CGs (herd, year and season of birth, management group at birth and weaning, and sex) and age of animal at recording and age of dam at calving (linear and quadratic effects) as covariate; WG: CGs (herd, year and season of birth, management group at weaning and yearling, and sex) and number of days from weaning to yearling (linear effect) and age of dam at calving (linear and quadratic effects) as covariate; AFC: CGs (herd, year and season of birth and breeding season); MW: CGs (herd, year and season of recording, and management group at weaning and at yearling) and age of animal at recording (linear and quadratic effects), as covariate. For SR, CGs showing no variability - i.e., all animals present the same response category ( 0 or 1$)$ - were eliminated. For other traits, records outside the acceptable range - i.e., \pm 3 standard deviations of the mean of the $\mathrm{CG}$ - and CGs with fewer than 4 observations were excluded. The general structure of the dataset analyzed is shown in Table 1. 


\section{Analyses}

(Co)variance components were estimated with Bayesian inference in three-trait analyses that always included SR and WW. A nonlinear (threshold) animal model was used for SR and a linear animal model for WW, WG, AFC, and MW. The THRGIBBSF90 program (Misztal et al., 2002) was used, which permits the study of categorical and continuous traits in the same analysis.

The matrix representation of the general model used is the following:

$$
y=X \beta+Z_{1} a+Z_{2} m+W c+e,
$$

(Equation 1)

where $y$ is the vector of observations, $\beta$ is the vector of systematic effects, $a$ is the vector of direct additive genetic random effects of each animal, $m$ is the vector of maternal genetic random effects, $c$ is the vector of random effects of the maternal permanent environment, and $e$ is the vector of residual random effects. $X, Z_{1}, Z_{2}$, and $W$ are incidence matrices that relate the records to the systematic effects and direct additive genetic, maternal genetic, and maternal permanent environmental random effects, respectively. We assumed that the direct additive genetic, maternal genetic, and maternal permanent environmental effects were not correlated with the residual effect. Maternal (genetic and permanent environmental) effects were only included for WW. The covariance structure of the random effects can be described as follows:

$$
\operatorname{Var}\left[\begin{array}{c}
a \\
m \\
c \\
e
\end{array}\right]=\left[\begin{array}{cccc}
G \otimes A & A \sigma_{a m} & 0 & 0 \\
A \sigma_{a m} & A \sigma_{m}^{2} & 0 & 0 \\
0 & 0 & I_{N m} \sigma_{c}^{2} & 0 \\
0 & 0 & 0 & R \otimes I_{N}
\end{array}\right],
$$

where $G$ is the (co)variance matrix of direct additive genetic effects, $\otimes$ is the direct product between matrices, $A$ is the relationship matrix, $\sigma_{m}^{2}$ is the maternal genetic variance, $\sigma_{c}^{2}$ is the covariance between direct additive genetic and maternal genetic effects, $\sigma_{a m}$ is the covariance between direct additive genetic and maternal genetic effects, $I$ is the identity matrix, $R$ is the (co)variance matrix of residual effects; $\mathrm{Nm}$ is the number of dams of animals with records, and $N$ is the number of animals with records.

Uniform a priori distribution was defined for systematic effects with $\beta \propto$ constant. The prior variance-covariance matrices of all random effects were sampled from inverted Wishart distributions (IW) with the following:

$$
\begin{gathered}
G \mid v_{g}, V_{g} \sim I W\left(v_{g} V_{g}, v_{g}\right), \\
R \mid v_{e}, V_{e} \sim I W\left(v_{e} V_{e}, v_{e}\right),
\end{gathered}
$$

where $v_{i}$ and $V_{i}(i=g, e)$ are hyperparameters of the distributions, which are assumed known. $I W$ reduces to improper uniform distribution if $v_{\mathrm{i}}$ is $-(k+1)$ and $V_{i}$ is 0 with a $k$ of 3 (Sorensen and Gianola, 2002). The conditional posterior distributions of the effects $\beta, \mathrm{a}, \mathrm{m}, \mathrm{c}$, and e were sampled from multivariate normal distributions.

The SR is a threshold trait. A threshold model was used, assuming that the underlying distribution (U) is determined by: 


$$
\mathrm{U} \sim \mathrm{N}\left(X \beta+Z_{I} a, I \sigma_{e}^{2}\right)
$$

(Equation 4)

The a priori distributions for direct additive genetic and residual effects followed multivariate normal distributions. Because the variable in the underlying distribution is not observable, the assumption of $\sigma_{e}^{2}=1$ is generally adopted to obtain identifiability in the likelihood function (Sorensen and Gianola, 2002). According to Gianola and Foulley (1983), after the model parameters have been defined, the connection between categorical and continuous scales can be established in such a way that the probability of an observation belonging to the first category is proportional to the following:

$$
\mathrm{P}\left(\mathrm{y}_{\mathrm{r}}=0 \mid \mathrm{t}, \theta\right)=\mathrm{P}\left(\mathrm{U}_{\mathrm{r}}<\mathrm{t} \mid \mathrm{t}, \theta\right)=\phi\left(\left(\mathrm{t}-\mathrm{W}_{\mathrm{r}}^{\prime} \theta\right) / \sigma_{\mathrm{e}}\right),
$$

(Equation 5)

where $y_{r}$ is the response variable for the $\mathrm{r}^{\text {th }}$ observation, assuming a value of 1 or 2 if the observation belongs to the first or second category, respectively, and $t$ is the threshold. Because $t$ cannot be estimated, an arbitrary value is attributed. $U_{r}$ is the value of the underlying variable for the mentioned observation, $\phi()$ is the cumulative distribution function of a normal standard variable; $W_{r}^{\prime}$ is the incidence column vector that relates $\phi$ to the $\mathrm{r}^{\text {th }}$ observation, $\phi$ is the $\left(b^{\prime}, a^{\prime}\right)$ vector of location parameters of order s with $b$ (systematic effects) and $a$ (random effects).

A chain of 600,000 iterations was computed, with the final chain length, burn-in period, and thinning interval defined based on the criterion of Raftery and Lewis (1992), in which a low serial correlation between cycles indicates convergence of the chain. The Bayesian Output Analysis package of the R program (R Development Core Team, 2008) was used for the analysis. After confirmation of the convergence of the Gibbs chain, estimates of the posterior distribution were computed using a burn-in period of 100,000 iterations and a thinning interval of 50 iterations, for a total of 10,000 cycles. For SR and WW, estimates of heritabilities and correlations were calculated as the means of the results obtained from the three-trait analyses.

\section{RESULTS}

In the dataset studied, the mean SR of primiparous females was $73 \%$ (see Table 1). The heritabilities estimated with Bayesian inference in three-trait analyses for the traits studied are shown in Table 2. The mean, mode, and median estimates of heritabilities were close, as expected for a marginal posterior density that follows a normal distribution (Carlin and Louis, 2000; Aspilcueta-Borquis et al., 2010).

Table 1. Description of the dataset for subsequent rebreeding (SR) of heifers, weaning weight (WW), weight

\begin{tabular}{|c|c|c|c|c|c|}
\hline Trait & No. of observations & Mean \pm SD & Sires & Cows & $\mathrm{CG}$ \\
\hline$\overline{\mathrm{SR}(\%)}$ & 23,970 & 72.91 & 320 & 15,996 & 135 \\
\hline WW (kg) & 126,816 & $171.13 \pm 25.97$ & 488 & 43,978 & 2,318 \\
\hline WG $(\mathrm{kg})$ & 47,245 & $95.40 \pm 30.21$ & 390 & 21,962 & 1,550 \\
\hline $\mathrm{AFC}$ (days) & 33,233 & $1,062.06 \pm 114.99$ & 404 & 20,841 & 134 \\
\hline MW (kg) & 3,290 & $434.59 \pm 45.15$ & 193 & 3,036 & 46 \\
\hline
\end{tabular}
gain from weaning to yearling (WG), age at first calving (AFC), and mature cow weight (MW).

$\mathrm{SD}=$ standard deviation; $\mathrm{CG}=$ contemporary group. 
Table 2. Posterior estimates of direct $\left(h^{2}\right)$ and maternal $\left(h^{2}{ }_{m}\right)$ heritabilities for heifer subsequent rebreeding (SR), weaning weight (WW), weight gain from weaning to yearling (WG), age at first calving (AFC), and mature cow weight (MW), in Nellore cattle.

\begin{tabular}{|c|c|c|c|c|c|}
\hline \multirow[t]{2}{*}{ Trait } & \multicolumn{5}{|c|}{ Parameter } \\
\hline & & Mean \pm SD & Mode & Median & HPD (95\%) \\
\hline SR & $h^{2}$ & $0.18 \pm 0.02$ & 0.17 & 0.18 & $0.15-0.20$ \\
\hline \multirow[t]{2}{*}{ WW } & $h_{a}^{2}$ & $0.21 \pm 0.01$ & 0.21 & 0.21 & $0.19-0.22$ \\
\hline & $h^{2}{ }_{m}$ & $0.07 \pm 0.01$ & 0.07 & 0.07 & $0.06-0.08$ \\
\hline WG & $h_{a}^{2}$ & $0.30 \pm 0.01$ & 0.30 & 0.30 & $0.28-0.32$ \\
\hline $\mathrm{AFC}$ & $h_{a}^{2}$ & $0.21 \pm 0.01$ & 0.21 & 0.21 & $0.19-0.23$ \\
\hline MW & $h^{2}{ }_{a}$ & $0.45 \pm 0.04$ & 0.45 & 0.45 & $0.43-0.47$ \\
\hline
\end{tabular}

$\mathrm{SD}=$ standard deviation; HPD $(95 \%)=$ highest posterior density interval containing $95 \%$ of the observations.

The posterior means of heritability for SR was $0.18 \pm 0.02$ (see Table 2). The direct heritabilities estimated for WW, AFC, and WG were moderate, with values of $0.21 \pm 0.01$, $0.21 \pm 0.01$, and $0.30 \pm 0.01$, respectively. Conversely, a higher value of heritability was estimated for MW, with a mean of $0.45 \pm 0.04$. The maternal heritability estimated for WW was $0.07 \pm 0.01$.

The posterior densities of genetic correlations between SR and WW, WG, AFC, and MW are shown in Figure 1. The posterior mean estimates of genetic correlations between SR and productive traits were $-0.20 \pm 0.06(\mathrm{WW}), 0.31 \pm 0.07$ (WG), and $-0.15 \pm 0.09$ (MW; see Table 2). The posterior mean of the genetic correlation between SR and AFC was high and negative $(-0.77 \pm 0.05)$.

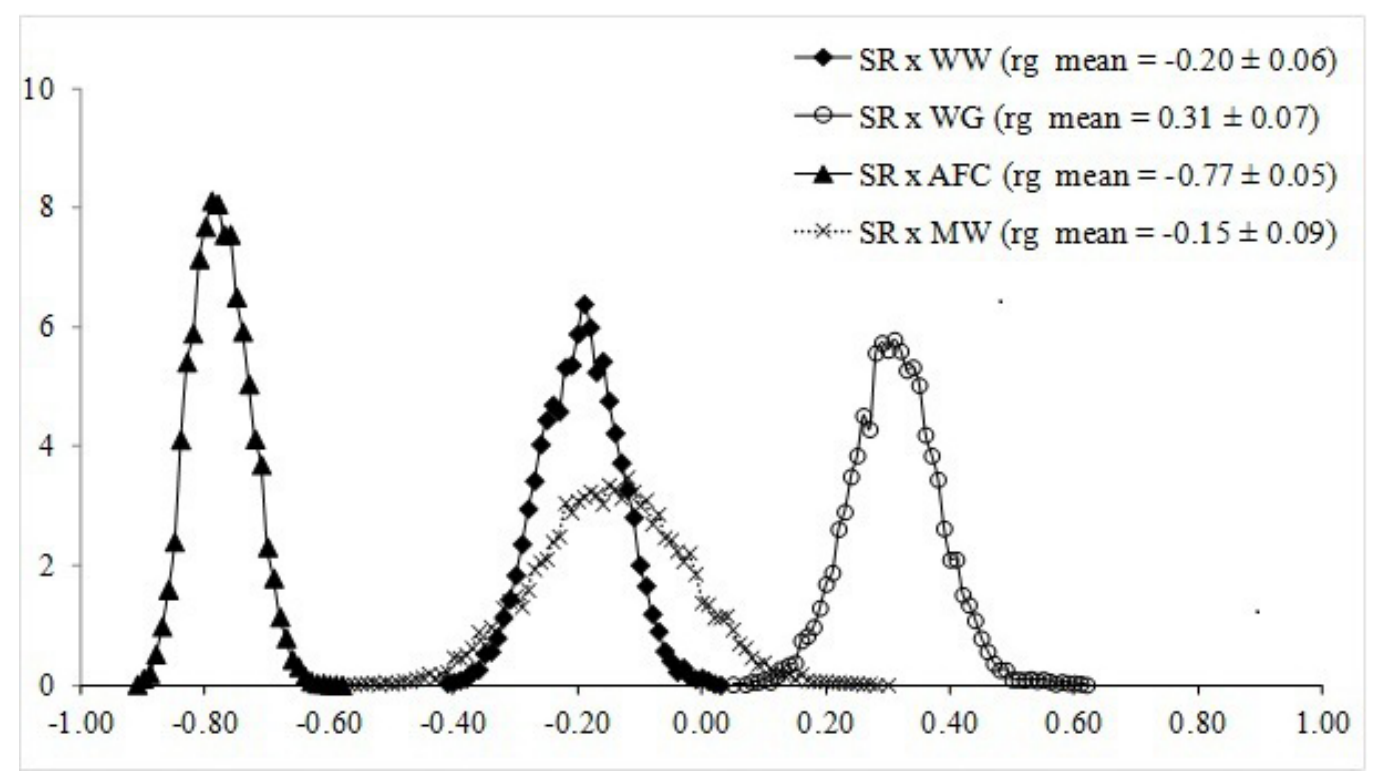

Figure 1. Posterior densities of genetic correlations ( $\mathrm{rg}$ ) between heifer subsequent rebreeding (SR) and weaning weight (WW), weight gain from weaning to yearling (WG), age at first calving (AFC), and mature cow weight (MW). 


\section{DISCUSSION}

The higher rate of heifer SR obtained in the present study might be explained in part by the fact that records of heifers exposed at 16 and 24 months of age were used; thus, heifers that conceives at 16 months of age (first breeding season) had a longer rest period from first calving to rebreeding and consequently better body condition, increasing the pregnancy rate of primiparous females exposed in the breeding season that followed. Also studying Nellore animals, Mercadante et al. (2003) and Silva et al. (2008) have reported mean SR rates of 59 and 53\%, respectively, for primiparous females mated at approximately 2 years of age.

The heritability estimated for SR of primiparous females suggests that the application of this trait as a selection criterion in the population studied may increase the number of heifers that conceive again in the subsequent breeding season. The heritability estimated in the present study is similar to the value of $0.16 \pm 0.05$ obtained by Silva et al. (2008) for sexually active Nellore females using Bayesian inference. Mercadante et al. (2003) have estimated a lower heritability $(0.10 \pm 0.07)$ for SR of Nellore heifers at 3 years of age using a threshold animal model. Conversely, Buddenberg et al. (1989) have reported a heritability of $0.32 \pm 0.03$ using weighted least squares with a mixed-model procedure (sire model) for SR in Angus females. Nellore heifers have, in average, later ages at puberty than those of females of Bos taurus, which can cause differences in the genetic variability of heifer pregnancy in these populations.

Using part of the same dataset examined in the present study and analyzing it with a survival model, Pereira (2008) estimated heritabilities of 0.11 and 0.18 for SR rates of females exposed at 24 months of age (normal breeding season) and of 0.08 and 0.13 when including all females (exposed at 16 and 24 months of age) on logarithmic and original scales, respectively. According to the author, these results indicate that the inclusion of data from sexually precocious animals reduced genetic variability and, consequently, estimated heritability. In the present study, all available data of females were included, regardless of whether the animals were exposed during the first or the normal breeding seasons, and the mean heritability was slightly higher than that reported by Pereira (2008).

The direct heritabilities estimated for WW, AFC, and WG indicate that part of the variation in these traits is determined by the additive effects of genes and that these traits should respond to selection. The heritabilities estimated in the present study are within the range reported in the literature for Nellore cattle, with estimates of 0.22-0.55 for WW, 0.170.20 for AFC, and 0.25-0.30 for WG (Pereira et al., 2001, 2002; Van Melis et al., 2010; Boligon et al., 2010, 2011). Similarly, maternal heritability $(0.07 \pm 0.01)$ for WW was similar to estimates obtained in other Nellore herds (Pereira et al., 2001; Boligon et al., 2010).

The heritability estimated for MW suggests the possibility of using this trait in population studies as a tool for the evaluation and identification of biotypes that are compatible with the production system, because direct selection for MW should lead to changes in female size and, consequently, nutritional requirements. Similar results have been reported in the literature when a single weight record obtained close to an age considered to be the adult age is used (Boligon et al., 2009, 2010).

In the Nellore herds studied, the genetic correlation estimated between SR and WG $(0.31$ \pm 0.07 ) suggests that selection for higher WG should result from long-term increases in SR rates in primiparous females. This finding differs from results reported by Mercadante et al. (2003), who used data from an experimental Nellore herd selected for higher postweaning weight and observed no differences in SR rates between controls and selected herds. Data on the genetic association between heifer SR and growth traits such as weight gain are scarce in the literature. 
In the population studied, the high and negative genetic correlation estimated between SR and AFC indicates that the use of AFC as a selection criterion to anticipate the onset of reproductive life should increase heifer SR rates. Females that conceive at a young age are generally still in the growth phase, and the physiological requirements of these animals during pregnancy and subsequent lactation are expected to be higher. However, the longest rest period between the first and second calving available for primiparous sexually precocious females can promote an increase in the pregnancy rate.

Studying Nellore herds, Pereira et al. (2001) have estimated low negative genetic correlations between the AFC of females exposed at 14 and 26 months of age and postweaning weight gain $(-0.08$ and -0.03 , respectively). These authors have suggested the existence of a threshold of weight gain below which female reproduction is compromised. Once the minimum threshold of weight gain that does not compromise the onset of puberty is reached, all animals show a similar performance. Boligon et al. (2010) have reported higher genetic correlations between $\mathrm{AFC}$ and weight gains from weaning to 12 months of age and from 12 to 18 months of age (-0.29 and -0.32 , respectively).

The genetic correlations between SR and WW (-0.20 \pm 0.06$)$ and MW (-0.15 \pm 0.09$)$ suggest that selection for higher WW should interfere with heifer SR rates, because WW is one of the main traits considered in the selection index of this population. Within this context and in view of the importance of these traits for the productive efficiency of beef cattle herds, the biological and technical limits to increasing WW without decreasing the heifer SR rate still require investigation. Moreover, these results suggest that heifer SR may be included in selection indices designed to improve female reproductive performance in the studied population without important changes in MW of the dams. We found no studies in the literature associating heifer SR with WW and MW.

The genetic associations estimated between heifer SR and WW and WG were contradictory, suggesting that heavier animals at weaning tend to present smaller long-term SR rates. These results imply that compensatory growth acts after weaning, i.e., animals with lower WW and therefore greater SR have increased postweaning growth. Thus, primiparous Nellore females that present higher postweaning weight gains would be favored in terms of their capacity to conceive in the following breeding season. In a recent study, Pereira (2008) has demonstrated the existence of a negative and moderate genetic correlation $(-0.66 \pm 0.05)$ between SR of heifers exposed at 24 months of age and yearling weight. In view of the lack of reports investigating the association between heifer SR and growth traits, further studies including different populations or breeds are needed to confirm the results obtained so far.

Per the results of this study, selection for higher WG and younger AFC may increase heifer SR rates. The inclusion of primiparous female SR in selection indices should result in the long-term improvement of heifer SR without important changes in MW.

\section{ACKNOWLEDGMENTS}

Research supported by Fundação de Amparo à Pesquisa do Estado de São Paulo. We are indebted to the Agropecuária Jacarezinho Ltda. for the use of the dataset.

\section{REFERENCES}

Aspilcueta-Borquis RR, Araujo Neto FR, Baldi F, Bignardi AB, et al. (2010). Genetic parameters for buffalo milk yield and milk quality traits using Bayesian inference. J. Dairy Sci. 93: 2195-2201. 
Boligon AA, Albuquerque LG, Mercadante MEZ and Lobo RB (2009). Herdabilidades e correlações entre pesos do nascimento à idade adulta em rebanhos da raça Nelore. Rev. Bras. Zootec. 38: 2320-2326.

Boligon AA, Albuquerque LG, Mercadante MEZ and Lobo RB (2010). Study of relations among age at first calving, average weight gains and weights from weaning to maturity in Nellore cattle. Rev. Bras. Zootec. 39: 746-751.

Boligon AA, Baldi F and Albuquerque LG (2011). Genetic parameters and relationships between growth traits and scrotal circumference measured at different ages in Nellore cattle. Genet. Mol. Biol. 34: 225-230.

Buddenberg BJ, Brown CJ, Johnson ZB, Dunn JE, et al. (1989). Heritability estimates of pregnancy rate in beef cows under natural mating. J. Anim. Sci. 67: 2589-2594.

Carlin BP and Louis TA (2000). Bayes and Empirical Bayes Methods for Data Analysis. Chapman \& Hall, London.

Gianola D and Foulley JL (1983). Sire evaluation for ordered categorical data with a threshold model. Genet. Sel. Evol. 15: 201-224.

Jenkins TG and Ferrell CL (1994). Productivity through weaning of nine breeds of cattle under varying feed availabilities: I. Initial evaluation. J. Anim. Sci. 72: 2787-2797.

Mercadante ME, Packer IU, Razook AG, Cyrillo JN, et al. (2003). Direct and correlated responses to selection for yearling weight on reproductive performance of Nelore cows. J. Anim. Sci. 81: 376-384.

Meyer K, Johnston DJ and Graser HU (2004). Estimates of the complete genetic covariance matrix for traits in multi-trait genetic evaluation of Australian Hereford cattle. Aust. Agric. Res. 55: 195-210.

Misztal I (2002). THRGIBBSF90 Family of Programs. Available in [http://nce.ads.uga.edu/ ignancy/ newprograms. html]. Accessed February 2, 2010.

Pereira E, Eler JP and Ferraz JBS (2001). Análise genética de algumas características reprodutivas e suas relações com o desempenho ponderal na raça Nelore. Arq. Bras. Med. Vet. Zootec. 53: 720-727.

Pereira E, Eler JP and Ferraz JBS (2002). Análise genética de características reprodutivas na raça Nelore. Pesq. Agropec. Bras. 37: 703-708.

Pereira MC (2008). Avaliação Genética da Reconcepção de Fêmeas Primíparas da Raça Nelore. Master’s thesis, Faculdade de Ciências Agrárias e Veterinárias, Universidade Estadual Paulista "Júlio de Mesquita Filho", Jaboticabal.

R Development Core Team (2008). R: A Language and Environment for Statistical Computing. ISBN 3-900051-07-0. R Foundation for Statistical Computing, Vienna. Available at [http://www.R-project.org]. Accessed January 20, 2009.

Raftery AE and Lewis SM (1992). Comment: one long run with diagnostics: implementation strategies for markov chain Monte Carlo. Statist. Sci. 7: 493-497.

Regatieri IC, Boligon AA, Baldi F and Albuquerque LG (2012). Genetic correlations between mature cow weight and productive and reproductive traits in Nellore cattle. Genet. Mol. Res. 11.

Silva JAV, Bignardi AB, Eler JP, Ferraz JBS, et al. (2008). Análises alternativas no estudo da reconcepção de novilhas Nelore. Rev. Cienc. Prod. Anim. 65: 131-135.

Sorensen D and Gianola D (2002). Likelihood, Bayesian, and MCMC Methods in Quantitative Genetics. Statistics for Biology and Health. Springer, New York.

Van Melis MH, Oliveira HN, Eler JP, Ferraz JB, et al. (2010). Additive genetic relationship of longevity with fertility and production traits in Nellore cattle based on bivariate models. Genet. Mol. Res. 9: 176-187.

Vieira A, Lobato JFP, Corrêa ES, Torres Júnior RA, et al (2005). Desempenho Produtivo nas Fases de Cria e Recria em um Sistema de Produção de Gado de Corte no Brasil Central. Embrapa Gado de Corte. (EMBRAPA-CNPGC. Boletim de Pesquisa e Desenvolvimento, 18), Campo Grande. 